\title{
MATERIAS QUE ABORDA LA SENTENCIA DEL TRIBUNAL CONSTITUCIONAL NUM 214/1989, DE 21 DE DICIEMBRE, EN RELACION CON DETERMI- NADOS ARTICULOS DE LA LEY REGULADORA DE LAS BASES DE REGIMEN LOCAL
}

\author{
POR \\ Francisco JAVIER FERNÁNDEZ GONZÁLEZ \\ Seminario de Derecho Administrativo. Universidad de Oviedo
}

\begin{abstract}
Dada la indudable importancia que para la Administración Local y Autonómica tiene la Sentencia del Tribunal Constitucional de 21 de diciembre de 1989, he considerado oportuno llevar a cabo un resumen más pormenorizado de las distintas materias a las que hace referencia el Alto Tribunal, sin que ello suponga una alteración del esquema con el que vienen realizándose las reseñas en estas sección de Jurisprudencia Constitucional:
\end{abstract}

Consideraciones previas sobre el significado y el alcance de la LRBRL.

- Debe ser el legislador estatal, con carácter general y para todo tipo de materias, el que fije unos principios o bases relativos a los aspectos institucionales (organizativos y funcionales) y a las competencias locales, encontrando cobertura a esa encomienda estatal en el concepto mismo de «bases de régimen jurídico de las Administraciones Públicas", por cuanto dicha expresión engloba a las Administraciones Locales.

- El «régimen local», que es, por tanto, el «régimen jurídico de las Administraciones Locales", resulta de este modo no una materia evanescente, disgregada en una pluralidad de asuntos sometidos a un régimen jurídico competencial diversificado, sino una materia con perfiles propios que, por imperativo de la garantía institucional de la autonomía local, contempla también - y no excluye - lo relativo a las competencias de los Entes locales.

- Por ellos, podrá si acaso discutirse el alcance dado a las competencias del Estado derivadas del art. 149.1.18 de la Constitución al incluir, en concreto, entre ellas, la de establecer los criterios básicos en materia de competencia de las Entidades locales, pero en absoluto se ajusta a la realidad la afirmación de que el «régimen local»-equivalente a «régimen jurídico de las Administraciones 
Locales»- haya quedado reducido a las cuestiones estrictamente organizativas.

Artículo 2 de la LRBRL: Las competencias de las Entidades locales. Su determinación por el legislador sectorial competente.

El artículo 2 de la LRBRL contiene dos previsiones dirigidas a concretar el alcance de la garantía constitucional de la autonomía local desde la perspectiva de las competencias locales:

a) Ningún reproche de inconstitucionalidad cabe formular a lo establecido en su párrafo 1.. , en el cual, se condena el criterio de que corresponde al legislador estatal la fijación de los principios básicos en orden a las competencias que deba reconocerse a las Entidades locales, estableciendo, y garantizando, al fin, «su derecho a intervenir en cuantos asuntos afecten directamente al círculo de sus intereses» y fijando al respecto unas directrices que se concretan en atender, en cada caso, a las características de la actividad pública y a la capacidad de gestión de la Entidad Local, de acuerdo con los principios de descentralización y máxima proximidad de la gestión administrativa de los ciudadanos. Fijados estos criterios, la LRBRL concerta algo más al delimitar las materias en las que necesariamente, de acuerdo con los principios señalados, a las Entidades locales deberán atribuírseles competencias, e incluso, especificando para los municipios los servicios mínimos que, en todo caso deberán prestar (arts. 25.2, 26 y 36$)$.

Delimitada así la exigencia de orden competencial vinculada a la garantía constitucional de la autonomía de las Entidades locales, la concreción última de las competencias locales queda remitida a la correspondiente legislación sectorial, ya sea estatal o autonómica, según el sistema constitucional de distribución de competencias entre el Estado y las Comunidades Autónomas.

b) El párrafo 2. del artículo 2 requiere un fallo interpretativo, en el sentido de que las leyes básicas deberán decir qué competencias corresponden en una materia compartida a las Entidades locales por ser ello necesario para garantizarles su autonomía (arts. 137 y 140 $\mathrm{CE}$ ). Ello no asegura que la ley básica estatal y sectorial (montes, sanidad, etc.) que tal cosa disponga sea, sin más, constitucional porque si excede de lo necesario para garantizar la institución de la autonomía local habrá invadido competencias comunitarias y será por ello inconstitucional, correspondiendo en último término al TC ponderar, en cada caso, si las competencias de ejecución atribuidas a los Entes locales son o no necesarias para asegurar su autonomía. En consecuencia, el art. 2.2 es constitucional interpretado en este sentido. 
Párrafo 2. del artículo 4 de la LRBRL: Las competencias de las Entidades locales no necesarias o contingentes

- El artículo 4.2 establece que «lo dispuesto (...) en el art. 2, podrá ser de aplicación a las Entidades territoriales de ámbito inferior al municipal y, asimismo, a las Comarcas, Areas metropolitanas y demás Entidades locales ...». La remisión que se hace al artículo 2 viene a abrir la posibilidad de que los criterios allí establecidos en orden a la asignación o atribución de competencias a los Municipios, Provincias e Islas, puedan ser también aplicados a estas otras entidades locales no necesarias.

- Tal posibilidad debe estimarse incursa en inconstitucionalidad por ser contraria al sistema de distribución de competencias de materia de régimen local entre el Estado y las Comunidades Autónomas, ya que el Estado viene a incidir sobre unas Entidades que sólo las Comunidades Autónomas pueden crear. Estas Entidades entran en cuanto a su propia existencia en el ámbito de disponibilidad de las Comunidades Autónomas que dispongan de la correspondiente competencia. Se trata de unas Entidades con un fuerte grado de «interiorización» autonómica, por lo que, en la determinación de sus niveles competenciales, el Estado no puede sino quedar al margen, correspondiendo en exclusiva a las Comunidades Autónomas determinar y fijar las competencias de las Entidades locales que procedan a crear en sus respectivos ámbitos territoriales.

- Por tanto, el inciso "y en el art. 2" del art. 4.2 LRBRL, debe considerarse inconstitucional, por cuanto la posibilidad que prevé de que el Estado pueda atribuir competencias a las Entidades locales referidas en el art. 3.2 de la misma Ley, resulta contraria al orden constitucional de distribución de competencias.

\section{Artículo 5: El orden de prelación de fuentes en el Derecho local}

- El art. 5 LRBRL establece el orden de prelación de normas aplicables a las distintas materias que conciernen a la Administración Local. En cuanto que enumera las normas aplicables en una materia en la que la competencia legislativa está dividida entre el Estado y las Comunidades Autónomas, el precepto ha de ser entendido, en consecuencia, como una norma interpretativa de lo dispuesto en el bloque de la constitucionalidad respecto de esta materia. Es esta naturaleza de norma meramente interpretativa, sin contenido material alguno, la que hace el precepto constitucionalmente ilegítimo. El orden de fuentes en un ordenamiento compuesto es el establecido por el bloque de la constitucionalidad, sin que uno de los elementos de esta realidad compuesta, en este caso el legislador estatal, puede imponer a todos los demás, como única interpretación posible, la que él mismo hace. 
- Por lo tanto, prescindiendo de la afirmación preliminar de la prioridad absoluta de la propia LRBRL que, naturalmente existirá en la medida en la que sus preceptos puedan apoyarse en los títulos competenciales que el Estado ostenta, el resto de los párrafos que el art. 5. contiene establecen un orden de prelación de fuentes que será dispuesto en el bloque de la constitucionalidad, e incorrecto en cuanto se aparte de él. En cuanto tal coincidencia exista, el precepto es en consecuencia superfluo y en cuanto no exista inválido. Su anulación no origina por tanto vacío alguno.

- Todas las remisiones al art. 5.o han de considerarse eliminadas al haber sido anulado su término de referencia, sin que la supresión de la referencia concreta tenga otro sentido que el puramente formal y que, en consecuencia, la legislación aplicable haya de ser la que efectivamente resulte de la normativa vigente con independencia de que se encuentre o no mencionada en el precepto suprimido.

\section{Artículos 20.2 (y por conexión el 20.1.c) y 32.2: Las competencias en} materia de organización de las Entidades locales.

- En lo concerniente a la organización municipal, el orden constitucional de distribución de competencias se funda en el reconocimiento de tres ámbitos normativos correspondientes a: la legislación básica del Estado, la legislación de desarrollo de las Comunidades Autónomas según los respectivos Estatutos y la potestad reglamentaria de los municipios.

- De acuerdo con este modelo constitucional, el apartado 1. del art. 20 LRBRL establece los órganos municipales de carácter necesario, reconociendo en el párrafo c) de este mismo apartado la potestad de autoorganización complementaria que corresponde a los propios municipios, lo que, en sí mismo, no plantea problema constitucional alguno. El problema surge en relación con el último inciso de este párrafo, según el cual, dicha potestad reglamentaria de autoorganización no tiene más límite que el respeto de los órganos necesarios establecidos por la Ley básica estatal. Con ello se elimina la posibilidad de todo espacio normativo para la legislación autonómica de desarrollo autonómico en materia de organización municipal, lo que contradice el orden constitucional de distribución de competencias antes descrito. Así, la declaración de inconstitucionalidad de este inciso está justificada por la exclusividad que como límite se atribuye a esta ley, lo que no impide que la LRBRL continúe, en cuanto Ley básica del Estado, constituyendo un límite (aunque no el único) a la Reglamentación organizativa de los Municipios.

- Por su parte, el apartado 2. del artículo 20 LRBRL reconoce formalmente la potestad legislativa de las Comunidades Autónomas para que éstas puedan establecer una organización municipal 
complementaria de la fijada con carácter básico o necesario por la propia LRBRL. No obstante, dicho reconocimiento queda supeditado en su último inciso al hecho de que «regirá en cada municipio en todo aquello que su Reglamento orgánico no disponga lo contrario». Ello significa que el espacio normativo de las Comunidades Autónomas, en este punto, queda también virtualmente desplazado en su totalidad por la prevalencia de los reglamentos orgánicos complementarios de que puedan dotarse los propios municipios. Por ello, este inciso también debe declararse contrario al orden constitucional de competencias.

- Depurado el art. 20 de estos dos incisos, se ajusta al orden constitucional de distribución de competencias, pues en el mismo se definen los órganos básicos municipales, se reconoce la potestad legislativa de desarrollo de las Comunidades Autónomas y se admite, al propio tiempo, la existencia de un ámbito reservado a la autonomía organizativa municipal, ámbito éste que no podrá ser desconocido o invadido por las normas que, en materia de organización municipal complementaria, dicten las Comunidades Autónomas.

- Todo lo afirmado en relación con el art. 20 puede también decirse del art. 32.2, ya que no suscita otro rechazo que el que deriva de los incisos «sin otro límite que el respeto a la organización determinada por esta Ley» y «que regirá en cada provincia en todo aquello en lo que ésta no disponga lo contrario, en ejercicio de su potestad de autoorganización". Despojado de ambos incisos el precepto no es inconstitucional, puesto que resulta respetuoso con las competencias legislativas de las Comunidades Autónomas en materia de organización provincial complementaria.

\section{Artículos 9 y 30: Regímenes locales especiales.}

- El art. 9 establece que las normas de desarrollo de la Ley que afecten a Entidades locales no podrán limitar su ámbito de aplicación a una o varias de dichas Entidades con carácter singular, sin perjuicio de lo dispuesto para los regímenes municipales o provinciales especiales. No supone la imposición de un uniformismo generalizado en el ejercicio de las competencias autonómicas, ni la imposibilidad de regímenes locales especiales, sino tan sólo veda el establecimiento de regímenes locales de carácter singular, es decir, con aplicación limitada a determinadas y concretas Entidades locales individualizadas por la propia norma. La prohibición de regímenes de caso único, singulares o particularizados constituye por su propia naturaleza una norma básica, que por su contenido no supone una restricción del ámbito de regulación propio de la Comunidad Autónoma, y es además una garantía adicional de la propia autonomía local, que podría 
resultar disminuida a través de la creación de normas de caso único por parte de la Comunidad Autónoma.

- El art. 30 ha previsto la posibilidad de que las leyes sobre régimen local de las Comunidades Autónomas puedan establecer regímenes especiales municipales «en el marco de lo establecido en esta Ley» para los municipios pequeños o de carácter rural y para aquellos que reúnan otras características que lo hagan aconsejable. No supone una retricción inconstitucional al legislador autonómico para establecer estos regímenes especiales: ni la expresión «en el marco de lo establecido en esta Ley" puesto que las competencias autonómicas han de sujetarse a las bases estatales establecidas en la propia LRBRL; ni la tipología que el precepto establece de los supuestos susceptibles de ser sometidos a un régimen especial, dado su carácter meramente descriptivo y ejemplificativo de los posibles supuestos de municipios susceptibles de ser sometidos, por la Ley autonómica, a un régimen especial.

\section{Artícula 13.2: Requisitos para la creación de nuevos Municipios.}

- El art. 13.2 al exigir para la creación de nuevos municipios, entre otras exigencias, la existencia de un «núcleo de población territorialmente diferenciado", no desconoce la realidad de Comunidades Autónomas como la de Galicia con una población dispersa diseminada, pues en la medida en que en el ámbito territorial de Galicia esa población dispersa o diseminada venga a formar un núcleo de población con suficiente entidad para ser calificado como tal, quedará plenamente satisfecha la exigencia legal que se analiza.

- Si bien el art. 13.2 irrumpe en el campo de la organización territorial, con ello, el Estado no se ha excedido de la competencia que le corresponde a fin de regular los requisitos que, con carácter necesario, deben reunir los municipios.

- Artículo 13.3: Estableciamiento de medidas que tiendan a fomentar la fusión de municipios.

- La habilitación al Estado para fomentar la fusión de municipios en nada restringe la competencia de las Comunidades Autónomas en orden a las alteraciones de términos municipales, las cuales corresponderá decretar al órgano autonómico competente, de acuerdo con la regulación propia de la Comunidad que sólo se encuentra limitada por las previsiones de orden procedimental y sustantivo que, respectivamente, prevén los párrafos 1 y 2 del mismo art. 13.

- En relación a las alteraciones municipales, sin perjuicio de 10 dispuesto por el art. 148.1 y 2 de la Constitución, el Estado ostenta 
también competencia para fijar los criterios básicos a los que debe sujetarse el ejercicio de las correspondientes competencias autonómicas, y ello como resultado del juego combinado de los arts. 137, 140 y 149.1.18 de la Constitución, que obligan necesariamente a atribuir al Estado la regulación básica de su propia estructura.

\section{Artículo 14.1: Cambios de denominación de los municipios.}

- El art. 14.1 condiciona la efectividad de la aprobación de los cambios de denominación de los Municipios a su inscripción en el Registro estatal de Entidades locales y a su subsiguiente publicación en el $\mathrm{BOE}$, pero tal previsión, que limita incuestionablemente la plenitud de efectos de las competencias ejecutivas autonómicas en materia de régimen local, merece el reconocimiento de su carácter de norma básica, por cuanto que reconoce a la Administración del Estado una competencia propia que es necesaria dado el ámbito nacional del interés afectado.

- La norma sólo condiciona el carácter oficial del cambio decidido por el poder público competente, lo cual es razonable para garantizar la seguridad jurídica. No correspondiendo ya al Estado la aprobación de los referidos cambios, el propio interés supraautonómico en que esos cambios o alteraciones sean conocidos con carácter general, justifica plenamente la previsión cuestionada, que no supone control del Estado, sino un medio de garantizar esa necesaria publicidad en todo el territorio por medio de la inscripción del cambio en el correspondiente Registro estatal y de su publicación en el BOE.

Artículo 27.3: Delegación de competencias del Estado a las Corporaciones Locales impuesta obligatoriamente por Ley.

- Se impugna el art. 27.3 en la medida que excepciona la regla general de que para la efectividad de la delegación estatal de competencias en favor de las entidades locales se requerirá «la previa consulta e informe de la Comunidad Autónoma», en aquellos supuestos en que "por Ley se imponga obligatoriamente» la delegación.

- EI TC entiende que la intervención de las Comunidades Autónomas se configura más como una posibilidad deseable y aconsejable, que como una exigencia inexcusable en todo caso, ya que, en estrictos términos constitucionales, nada impide la delegación o transferencia directa de competencias propias del Estado a las Corporaciones Locales. Además se trata de una atribución que, por su misma excepcionalidad, al mediar la correspondiente ley, justifica que se prescinda de la intervención preceptiva de la correspondiente Comunidad Autónoma. 
Artículo 28 y por conexión la Disposición Transitoria 2. a.2: La realización de actividades complementarias por los Municipios.

- El art. 28 no viene a ampliar notablemente el ámbito competencial de los municipios, tal y como queda ya delimitado por el art. 25 de la LRBRL, sino que dicho art. 28 se configura como una cláusula competencial genérica que habilita a los municipios para que puedan desarrollar actividades complementarias de las propias de otras Administraciones. Se trata de un reforzamiento de la autonomía local que no altera, por el propio carácter complementario de la actuación municipal, el orden constitucional de distribución de competencias.

- La Disposición Transitoria 2. ${ }^{\text {a }} 2$ al señalar que en las materias a que se refiere el art. 28 los municipios ostenten cuantas competencias de ejecución no se encuentren conferidas por la correspondiente legislación sectorial a otras Administraciones Públicas, no atribuye por sí misma competencia ejecutiva alguna, sino en función de la amplitud o detallismo con que el legislador sectorial $-y$, fundamentalmente, el legislador autonómico- venga a concretar la titularidad de las competencias de ejecución de esas materias, de modo que no supone quiebra alguna del reparto constitucional de competencias.

Artículo 42.2: Intervención de los Municipios en el procedimiento de creación de las Comarcas.

- El párrafo 2.. del art. 42 establece una serie de reglas procedimentales relativa a la creación de Comarcas, que son impugnadas por la C.A. de Galicia. Pero hay que tener en cuenta que en el Estatuto de Autonomía de Galicia la comarca no se configura como una entidad necesariamente integrante de la organización territorial de la C.A., de modo que la regulación y constitución de la comarca en Galicia no puede considerarse como resultante de la potestad de autoorganización de la propia C.A., sino como consecuencia de la competencia legislativa que sobre el régimen local ha asumido estatutariamente, desarrollando las bases legislativas estatales. En consecuencia, las comarcas no aparecen dotadas de ninguna garantía estatutaria, al no ser sino entes contingentes en función de la decisión que adopte el legislador autonómico, el cual, si bien podrá disponer sobre la constitución y creación de tales entes, deberá hacerlo, en todo caso, con sujeción a las exigencias determinadas por la legislación básica estatal, en concreto por el art. 42.2 de la LRBRL. Además, este párrafo 2.9 del art. 42 no desborde el concepto de "bases", dado que la posibilidad de que la voluntad municipal llegue a impedir la constitución de una determinada comarca se proyecta en la creación de un ente que ni es elemento necesario de la 
organización territorial de la C.A., ni goza, por ello, de garantía estatutaria alguna.

- No se produce una discriminación de la C.A. de Galicia respecto de la de Cataluña como consecuencia de la Disposición Adicional 4. ${ }^{a}$ de la LRBRL, según la cual la Generalidad de Cataluña no se verá total y absolutamente condicionada por las previsiones del art. 42.2. de la LRBRL, puesto que una hipotética oposición municipal, o provincial, en los términos previstos por el referido artículo, podrá ser superada en virtud de una ley aprobada por mayoría absoluta del Parlamento de Cataluña. Y no existe tal discriminación por dos razones: primero, porque se apoya en una justificación de orden histórico, como es el hecho de que Cataluña hubiera tenido aprobada en el pasado una organización comarcal para la totalidad de su territorio; y segundo, porque la posición competencial de Cataluña y Galicia en este singular aspecto no resulta equiparable, ya que Galicia, a diferencia de Cataluña, no ha previsto en su estatuto una «organización comarcal de carácter general».

\section{Artículo 42.4: Garantías competenciales a favor de los municipios agrupados en Comarcas.}

- La creación de nuevas entidades necesariamente ha de repercutir en la redistribución de los niveles competenciales de las entidades existentes, pero esa reacomodación competencial no puede ser a costa de eliminar las competencias de las entidades cuya autonomía queda constitucionalmente garantizada.

- En este precepto el legislador estatal ha fijado ese mínimo competencial que, en todo caso, debe corresponder a los municipios en virtud de la propia garantía institucional de que gozan. Ese mínimo queda concretado en la competencia para prestar los servicios que se enumeran en el art. 26 de la Ley, y en la garantía formulada, negativamente, de que no pueden quedar privados de toda intervención en cada una de las materias enumeradas en el art. 25.2. Quiere decirse, pues, que la creación de comarcas podrá repercutir en las competencias de los municipios agrupados en las mismas, pero tal hecho no puede en ningún caso desembocar en una abolición, por desapoderamiento total, de la autonomía municipal constitucionalmente garantizada.

- Este precepto no contradice tampoco la competencia de las Comunidades Autónomas en materia de alteraciones municipales, las cuales pueden plasmarse, incluso en la supresión de municipios; pero sí garantiza la institución municipal, que, aun en la hipótesis extrema, no podrá diluirse para pasar a identificarse con la comarca. El 42.4 marca un límite infranqueable a la redistribución de competencias que, como consecuencia de la creación de comarcas, puedan llevar a cabo las Comunidades Autónomas. 
Artículo 44.3.o. Procedimiento de aprobación de los Estatutos de las Mancomunidades de Municipios.

- La eliminación de la aprobación de los Estatutos de las Mancomunidades por la Administración de tutela (primero confiada a los órganos de tutela de la Administración estatal y luego a los de las Administraciones Autonómicas), no lesiona las competencias en materia de régimen local asumidas por la C.A. Galicia, por cuanto, con plena cobertura en el art. 149.1.18 de la Constitución, y adecuando plenamente la regulación al carácter y naturaleza de las Mancomunidades, el Estado ha considerado preferible, dentro de las soluciones constitucionalmente posibles, erradicar esa manifestación de tutela y, por lo tanto, implícitamente reconducir el control mismo de la adecuación a Derecho de tales Estatutos al régimen general del control jurisdiccional contencioso-administrativo.

- El art. 44.3. 9 no prescinde de toda iniciativa e intervención de la Comunidad Autónoma en la constitución de las Mancomunidades, pues comienza señalando que «el prodecimiento de aprobación de los Estatutos de las Mancomunidades se determinará por la legislación de las Comunidades Autónomas...", permitiendo así un desarrollo autonómico que, con respeto a. las bases estatales ( $y$, por tanto, a la competencia reservada a los propios municipios para la constitución de Mancomunidades y la aprobación de sus Estatutos), arbitre algún tipo de intervención que permita a la Comunidad Autónoma examinar definitivamente dichos Estatutos y poder así formular las observaciones de legalidad y demás sugerencias que estime pertinentes y le permita, con carácter previo a su aprobación por los propios municipios, poder proceder a su homologación o visado desde la estricta perspectiva de la legalidad.

\section{Artículo 45: Regulación de las entidades de ámbito territorial inferior al Municipio.}

- El art. 45 en su párrafo 1. remite la regulación de las «entidades de ámbito territorial inferior al Municipio» a lo que dispongan las leyes de las Comunidades Autónomas sobre régimen local, fijando, no obstante, en su párrafo 2. una serie de reglas en orden a la constitución, organización y funcionamiento de las mismas. Hay que examinar el alcance de estas reglas, a fin de controlar posibles excesos que pudieran despojarlas del carácter básico que le ha sido atribuido:

a) La primera consiste en que la iniciativa para la constitución de estas entidades locales corresponderá indistintamente a la población interesada o al Ayuntamiento correspondiente, el cual, no obstante, deberá ser oído en todo caso. Se establece así una garantía mínima que no limita indebidamente con las competencias autonómicas, pues no se cierra la posibilidad a que las propias leyes autonómicas 
concreten el alcance y sentido de la iniciativa municipal en orden a la constitución de estas entidades. La iniciativa no corresponde, en efecto, a la Comunidad Autónoma, pero esta iniciativa prosperará o no en función de la decisión última que ella misma venga a adoptar.

b) La regla contenida en el párrafo 2.b), apartados 1 y 2 de este artículo 45, se refiere a la organización de estas entidades de ámbito territorial inferior al Municipio. Esta organización se concreta en la necesidad de que la entidad cuente con un órgano unipersonal ejecutivo y un órgano colegiado de control, fijándose el número de miembros de éste y el procedimiento para su designación. Tales previsiones no pueden ampararse en la competencia reservada al Estado por el art. 149.1.18 de la Constitución, por cuanto se trata de una cuestión estrictamente organizativa que no presenta mayor incidencia en otros intereses generales de alcance supraautonómico, razón que impide calificar a las referidas previsiones como normas básicas; por tanto, carentes del carácter de normas básicas; estas previsiones no son de directa aplicación en el ámbito de la Comunidad Autónoma de Galicia.

c) La tercera y última regla garantiza una intervención del Ayuntamiento respectivo sobre determinados actos de estas entidades. Sin embargo, en nada lesiona las competencias autonómicas la previsión de que los acuerdos expresamente enumerados (relativos a disposiciones de bienes, operaciones de crédito y expropiación forzosa) deban ser ratificados por el Ayuntamiento del término municipal en que se encuentre incardinada la entidad, ya que se trata de entidades que, aun cuando aparezcan dotadas de personalidad jurídica, no dejan de formar parte de la entidad municipal, actuando en un régimen de descentralización que, si bien a la legislación autonómica corresponderá precisar, justifica que, como garantía misma de la institución municipal, el legislador estatal le atribuya a ésta una cierta facultad de tutela referida a un catálogo tasado de supuestos de incuestionable relieve para el propio municipio.

\section{Artículo 47.2. - c): Aprobación de la delimitación de los términos municipales.}

- Ningún desapoderamiento de la Comunidad Autónoma de Galicia cabe imputar a la previsión contenida en este precepto, pues se ciñe a exigir una determinada mayoría cualificada en los acuerdos municipales relativos a la aprobación de la delimitación de los términos municipales sin que por ello se prejuzgue la competencia que respecto de la resolución última sobre la delimitación, en caso de no alcanzarse los acuerdos necesarios o, incluso, en orden a la ratificación de tales acuerdos, pueda corresponder a la Comunidad Autónoma. 
Inciso final del art. 48: Solicitud del dictamen del Consejo de Estado «a través del Ministerio de Administración Territorial».

- La obligación que se prevé de que la solicitud del dictamen del Consejo de Estado sea cursada por conducto del Presidente de la Comunidad Autónoma «y a través del Ministerio de Administración Territorial», condiciona ilegítimamente las potestades propias de autogobierno de las Comunidades Autónomas, a la vez que se desconoce que los presidentes de estas Comunidades Autónomas, según prevén sus respectivos Estatutos, ostentan la representación ordinaria del Estado en el ámbito territorial de la propia Comunidad Autónoma, y que el Consejo de Estado, se configura también como órgano consultivo de las Comunidades Autónomas. Procede, en consecuencia, declarar inconstitucional el inciso «y a través del Ministerio de Administración Territorial».

Artículo 50.1: Funciones resolutorias de conflictos de atribuciones entre órganos de una misma Corporación Local.

El art. 50.1 establece la competencia del Pleno o del Alcalde o Presidente de la Corporación, según los casos, para la resolución de los conflictos de atribuciones que surjan entre órganos y entidades dependientes de una misma Corporación Local. Ello no desapodera a las Comunidades Autónomas, sino que, por el contrario, se justifica plenamente porque en estos conflictos es el propio interés de la Entidad lo que está en juego $y$, por tanto, lo que obliga a reconocerle la competencia para poner término al asunto. Cuando se trate de conflictos de competencias entre diferentes entidades locales pertenecientes a la misma Comunidad, se reconoce la competencia de la respectiva Comunidad Autónoma para su resolución.

Artículo 55, apartados a) y b): Respeto de las competencias de otras Administraciones y ponderación de los intereses públicos implicados.

- La tesis de que el art. 55 ap. a) y b) es una norma que integra y completa las prescripciones generales de la Constitución relativas al sistema de distribución de competencias, incurriendo por ello en inconstitucionalidad, debe ser rechazada, puesto que sus previsiones no vienen a integrar ni completar precisión constitucional alguna, sino a reiterar unas exigencias consustanciales al propio ejercicio por el Estado, las Comunidades Autónomas y las Entidades locales de las competencias que, con arreglo al bloque de la constitucionalidad, les corresponden.

\section{Artículo 58.1: Creación de órganos de colaboración}

- El art. 58 prevé la posibilidad de que, en virtud de ley, tanto el Estado como las Comunidades Autónomas puedan crear, «para la 
coordinación administrativa, órganos de colaboración de las Administraciones correspondientes con las Entidades locales». No obstante, se prevé que «tanto la Administración del Estado como las de las Comunidades Autónomas podrán participar en los respectivos órganos de colaboración establecidos por cada uno de ellas»; que tales órganos "serán únicamente deliberantes y consultivos», y que, finalmente, se habilita al Gobierno de la Nación para que «en materia de inversiones y de prestación de servicios», pueda crear en cada Comunidad Autónoma una "Comisión Territorial de Administración Local».

- Ninguna duda cabe acerca de la plena constitucionalidad de la previsión genérica de que el Estado, al igual que las Comunidades Autónomas, pueda crear esos órganos de colaboración con las Entidades locales, se recoge aquí una manifestación orgánica del principio de colaboración al que la propia estructura territorial del Estado necesariamente aboca.

- El cárácter bifronte del régimen local posibilita fórmulas cooperativas como ésta, en cuanto que las Entidades locales forman también parte de la oganización territorial del Estado y éste puede mantener legítimamente relaciones directas con aquéllas, sin que, en todo caso, sea imprescindible la mediación de las correspondientes Comunidades Autónomas.

- Lejos de marginar a las Comunidades Autónomas, se abre un importante cauce de participación al posibilitar la efectiva presencia de las Comunidades Autónomas en tales órganos. Posibilidad que se reproduce cuando sean las Comunidades Autónomas las que creen los órganos de colaboración.

- Las fórmulas orgánicas previstas responden a la idea de articular foros permanentes de relación entre las distintas Administraciones públicas, lo que explica que esos órganos de colaboración fundamentalmente asuman un carácter deliberante o consultivo. No son estrictas técnicas de coordinación las que se prevén, si bien los resultados que se pretenden alcanzar se orientan también a hacer efectiva la exigencia constitucional de coordinación en la actuación de las Administraciones Públicas (art. 103.1 de la Constitución).

- Respecto a la posibilidad de que el Gobierno cree en cada Comunidad Autónoma una Comisión Territorial de Administración Local para la materia de inversiones y de prestación de servicios, bien puede pensarse que esas Comisiones necesariamente responderán al carácter genérico con que el propio art. 58.1 en su apartado primero, configura a los órganos de colaboración, siendo aquéllas mera especificación de éstos, por lo que no faltan apoyaturas para estimar que esas Comisiones serán únicamente consultivas o deliberantes y que, en todo caso, podrán participar en ellas las correspondientes Comunidades Autónomas. 
Artículo 59.1: Coordinación de la actividad de la Administración local en los diversos sectores materiales.

- Lo que en el art. 59.1. se prevé es que cuando las técnicas de cooperación contempladas en los artículos anteriores no permiten alcanzar el fin previsto en los supuestos a los que se refiere el art. 10.2 , o bien dichas técnicas resultaran manifiestamente inadecuadas por razón de las características de la tarea pública de que se trate, las leyes del Estado y las de las Comunidades Autónomas reguladoras de los distintos sectores de la acción pública podrán atribuir al Gobierno de la Nación, $o$ al Consejo de Gobierno, la facultad de coordinar la actividad de la Administración local y, en especial, de las Diputaciones Provinciales en el ejercicio de sus competencias. $Y$ en los párrafos siguientes del mismo art. 59 se especifican una serie de reglas a las que, en todo caso, deberá ajustarse el ejercicio de la facultad coordinadora.

- En el art. 59.1 al Estado no se le atribuye indebidamente competencia alguna que no le corresponda a fin de coordinar la actuación de las Entidades locales, produciéndose así un desapoderamiento correlativo de las Comunidades Autónomas. Antes bien, hay una expresa remisión a los diversos sectores materiales en los que venga a fanifestarse la actuación administrativa que reclame esa coordinación, sin prejuzgar, por tanto, la titularidad misma de la competencia en cada caso.

- Esto no condiciona en absoluto que, frente a la hipotética atribución al Gobierno de la Nación de facultades de coordinación en cualesquiera de los sectores concretos de la acción pública, las Comunidades Autónomas que consideren vulnerado o invadido su específico ámbito competencial, por corresponderles a ellas constitucionalmente esas facultades, no puedan utilizar las vías procesales oportunas a fin de restablecer, en su caso, el orden de competencias constitucionalmente previsto.

Artículo 62: Participación de las Entidades locales en actuaciones o procedimientos conjuntamente con la Administración estatal o autonómica correspondiente.

- El art. 62 garantiza a las Entidades locales su participación o integración en actuaciones o procedimientos conjuntamente con la Administración estatal o autonómica correspondiente, cuando la naturaleza de la actividad de que se trate haga muy difícil o inconveniente una asignación diferenciada y distinta de facultades decisorias en la materia.

- La previsión se muestra respetuosa con las competencias autonómicas, por cuanto especifica que esa participación corresponde asegurarla a las correspondientes leyes reguladoras de la acción pública (sin prejuzgar, por tanto, su carácter estatal o autonómico), y 
que la decisión final quedará atribuida a la Administración titular según el propio sistema constitucional de distribución de competencias. Por tanto, en ninguna vulneración de ese orden constitucional de reparto de competencias incurre el precepto impugnado, ni tampoco lo hace en relación con el principio de seguridad jurídica.

Artículos 65 y 66: Impugnación de actos o acuerdos locales por la Administración estatal o autonómica.

Los artículos 65 y 66 presentan una incuestionable dimensión jurídico-procesal cuya regulación es de la exclusiva competencia del Estado en los términos dispuestos por el art. 149.1.6 de la Constitución. No se trata, en realidad, de un control, de los actos y acuerdos locales por la Administración estatal o autonómica, sino de la regulación de la legitimación precisa para la impugnación de los mismos ante la jurisdicción contencioso-administrativa. Por tanto, el título competencial que ampara ambos preceptos de la Ley, no es sólo el dimanante del art. 149.1.18 de la Constitución, sino que confluye también el previsto en el n.o 6 del mismo artículo del texto constitucional.

Artículo 67: Habilitación al Delegado del Gobierno para suspender aquellos actos o acuerdos de las Entidades locales que atenten gravemente al interés general de España.

- El carácter cautelar, el supuesto extraordinario y la necesidad de residenciar ante la jurisdicción en el máximo de 10 días la cuestión suscitada, conduce a desestimar la impugnación del precepto, que no invade competencia alguna al adoptar que tales medidas se lleven a cabo por el Delegado del Gobierno.

Artículo 68.3. Ejercicio por los vecinos de las acciones necesarias para la defensa de los bienes y derechos locales.

- El art. 68.3 habilita a los vecinos para ejercitar las acciones necesarias para la defensa de los bienes y derechos locales en el caso de que hubiesen requerido su ejercicio a la correspondiente entidad local sin que ésta, en el plazo de 30 días, lo hubiese hecho efectivo.

- Al haber eliminado la LRBRL la necesidad de autorización previa para el ejercicio de estas acciones, mal puede reivindicar para sí tal potestad la Comunidad Autónoma.

Artículo 83: Regulación de los montes vecinales en mano común por su regulación específica.

- El precepto alude a la «legislación específica» de los montes vecinales en mano común sin prejuzgar en forma alguna a quien corresponda dictar esa legislación. 
Art. 98: Selección, formación y habilitación de los funcionarios con habilitación de carácter nacional.

- El art. 98 prevé un sistema estatal y uniforme para la selección, formación y habilitación de funcionarios con habilitación de carácter nacional, con lo que el Estado trata de garantizar una formación común a partir de la cual puedan participar, sin perjuicio de alguna excepción, en los concursos de méritos convocados para la provisión de las plazas o puestos de trabajo a ellos reservados en las correspondientes plantillas de las Entidades Locales. Este sistema queda únicamente modulado al abrirse la posibilidad de descentralizar territorialmente por Comunidades Autónomas la realización de las pruebas selectivas para el acceso al curso de formación $y$, al establecer, asimismo, la obligación del Estado de celebrar convenios con los Institutos o Escuelas de funcionarios de las Comunidades Autónomas que así lo soliciten, a fin de encomendar a éstos, por delegación, la formación de los funcionarios que deseen obtener una habilitación de carácter nacional. En todo lo demás (convocatoria, bases y programas de la oposición o concurso-oposición, programas de formación, otorgamiento de la habilitación o nombramiento como funcionarios en prácticas, etc.) la competencia es del Estado.

- Pues bien, el detalle y minuciosidad con que en esta materia se ha manifestado el ejercicio de la competencia estatal sobre las bases del régimen jurídico de las Administraciones Públicas y el régimen estatutario de sus funcionarios, no determina que pueda acogerse la inconstitucionalidad del art. 98 de la LRBRL. Hay que reconocer como válida y ajustada plenamente a la Constitución la decisión del legislador estatal que ha fijado como básicas determinadas funciones que, por su propia naturaleza quedan reservadas a determinados funcionarios con un específico grado de formación. Ese carácter básico, al servicio de garantizar de manera generalizada en todas las Administraciones Locales el correcto desempeño y desenvolvimiento de cierto elenco de funciones que, por su trascendencia misma, rebasan el estricto interés local y, más aún, autonómico, justifica asimismo que el Estado asuma, con plenitud de facultades, la fijación de los correspondientes programas de selección y formación de los funcionarios habilitados.

Artículo 99: Sistema de provisión de plazas de los funcionarios con habilitación de carácter nacional. Fijación de los baremos.

- El art. 99.1 al no prever la intervención de las Comunidades Autónomas en la fijación del baremo que ha de contener los méritos 
generales y específicos para la resolución de los concursos de provisión de las plazas reservadas a los funcionarios con habilitación nacional, y ello a fin de que a través de esa intervención autonómica quede garantizada la inclusión como mérito del conocimiento de la lengua propia de la Comunidad, no vulnera ni lesiona competencia alguna de las Comunidades Autónomas, ya que esa garantía no es estricta y exclusiva responsabilidad de la Administración Autonómica que pueda por ello desplazar cualesquiera competencias de las Administraciones Locales que también forman parte de la Comunidad Autónoma. Y ello porque se trata de funcionarios al servicio de las Administraciones Locales que, en la medida en que también éstas forman parte de la Comunidad Autónoma bilingüe, deben atender igualmente a la obligación de garantizar el uso de las lenguas oficiales por los ciudadanos.

Disposición adicional segunda, apartados 7.o a 10: Especialidades de las Instituciones forales de los Territorios Históricos en materia de funcionarios con habilitación de carácter nacional.

- Aunque las recurrentes pretenden destacar que no pueden tener carácter básico los artículos 98 y 99 en la medida en que contemplan un régimen excepcional, como el amparado en la Disposición adicional segunda, apartados 7 a 10, hay que tener en cuenta que esa excepción, en el presente caso está fundada en la Disposición adicional primera de la Constitución, que «ampara y respeta los derechos históricos de los territorios forales». La Disposición

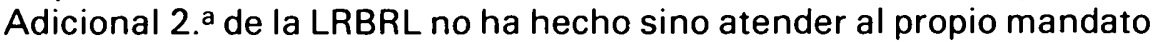
constitucional, preservando la singularidad misma de ese régimen foral en los aspectos organizativos, en unos términos y con un alcance perfectamente compatible con la propia Constitución.

- Por ello no pueden pretender las recurrentes que los derechos reconocidos a los territorios históricos sean extensibles a otras Comunidades Autónomas por el simple hecho de haber asumido idénticas competencias que la Comunidad Autónoma del País Vasco en materia de régimen local, dado el carácter particular o excepcional de los derechos reconocidos a los territorios históricos.

Artículo 106.3: Delegación de las competencias de las Entidades locales para la gestión, recaudación e inspección de sus tributos propios, de acuerdo con lo que establezca la legislación estatal.

- La competencia de las Entidades locales para la gestión, recaudación e inspección de sus tributos propios puede delegarse en favor de otros entes locales de ámbito superior o de las respectivas 
Comunidades Autónomas «de acuerdo con lo que establezca la legislación del Estado». Con esta precisión, el Estado no ha tratado sino garantizar un aspecto esencial del régimen competencial de las Entidades locales.

- Corresponde al Estado establecer las reglas ordenadoras de las delegaciones de competencias locales a favor de otras Entidades o de las propias Comunidades Autónomas, por ser un aspecto básico del régimen jurídico de las Administraciones Locales, sin que por ello se lesione competencia alguna de las Comunidades Autónomas.

\section{Artículo 115: Fiscalización de las Entidades Locales por el Tribunal de Cuentas, así como por la Sindicatura de Cuentas.}

- El art. 115 no incurre en inconstitucionalidad al establecer que «la fiscalización externa de la cuentas y de la gestión económica de las Entidades Locales corresponde al Tribunal de Cuentas, con el alcance y condiciones que establece la Ley Orgánica que lo regula y sin perjuicio de los supuestos de delegacón previstos en la misma", ya que ello no excluye que, en el ámbito territorial de Cataluña y con arreglo a la Ley 6/1984, de 5 de marzo, de Sindicatura de Cuentas, también corresponda a ésta la fiscalización externa de las cuentas y gestión económica de las Entidades Locales de Cataluña.

Artículo 116: Organización y funcionamiento de las Corporaciones Locales para la aprobación por ella de sus cuentas anuales.

- En el art. 116 no cabe apreciar tacha de inconstitucionalidad alguna, ya que se trata de una previsión relativa a la organización y funcionamiento de las Corporaciones Locales en orden a la aprobación por ellas mismas de sus cuentas anuales que encuentra plena cobertura en la competencia del Estado para fijar las bases del régimen jurídico de las Administraciones Públicas y que, consecuentemente, no vulnera la competencia en materia de régimen local de las Comunidades Autónomas.

\section{Artículo 117: La Comisión Nacional de Administración Local.}

- Respecto a una presunta vulneración de las competencias autonómicas en materia de régimen local, al no formar parte las Comunidades Autónomas de la Comisión Nacional de Administración Local, ya que, en todo caso, su presencia en las reuniones que la misma celebre queda supeditada a la previa invitación que se les formule, hay que señalar que nada obsta a que constitucionalmente la LRBRL haya podido articular dicha Comisión como un organismo de relación directa entre el Estado y las Entidades Locales en cuya composición queda excluida la presencia de las Comunidades Autónomas. Máxime cuando las funciones que los arts. 118 y 119 
atribuyen a la Comisión Nacional de Administración Local no suponen intromisión en las competencias autonómicas.

- La previsión de que «la designación de los representantes de las Entidades locales corresponde en todo caso a la asociación de ámbito estatal con mayor implantación», aunque aparezca como una norma incompleta, en nada incide en la posición constitucional de las Entidades locales, cuya autonomía no se ve afectada en manera alguna por semejante previsión.

\section{Disposición Final 1. a: Delegación legislativa al Gobierno.}

- Tanto la autorización al Gobierno de la Nación para refundir las disposiciones legales vigentes (lo que se ha plasmado en la aprobación del Real Decreto Legislativo 781/1986, de 18 de abril), que encuentra su plena cobertura constitucional en el art. 82.5 de la Constitución; como la habilitación al Gobierno para que, en uso de su potestad reglamentaria (art. 97 de la Constitución) actualice determinadas normas reglamenterias; no infringen requisito constitucional alguno.

- El hecho de que al Estado se le haya atribuido la competencia exclusiva para fijar las bases del régimen jurídico de las Administraciones Públicas, no le imposibilita para poder establecer un marco normativo general regulador del «régimen local», ya que el Derecho estatal es, en todo caso, supletorio del Derecho de las Comunidades Autónomas. La mera habilitación legal para que pueda dictarse esa normativa global o de conjunto no lesiona las competencias de las Comunidades Autónomas. No hay tampoco «uniformización» alguna del régimen local, porque con ello no se produce desapoderamiento competencial alguno de las Comunidades Autónomas. Antes bien, con ello el Estado atiende a una exigencia fundamental, la de prevenir un marco normativo general que venga a cubrir no sólo las consecuencias resultantes de los diferentes niveles competenciales existentes en la materia entre unas y otras comunidades, sino también la simple inactividad normativa que, transitoriamente o no, pueda producirse en aquellas Comunidades Autónomas con competencia para desarrollar las normas básicas estatales. Serán pues, las normas autonómicas que, ajustándose a las bases estatales, vayan dictándose las que, en todo caso, desplazarán en su aplicabilidad directa o eficacia territorial a esas otras normas estatales no básicas dictadas al amparo de la Disposición Final 1. a de la LRBRL. Todo ello, en fin, sin que nada obste a que, si el ejercicio de tales autorizaciones fuere incorrecto, o a las normas resultantes se les atribuyese un carácter y eficacia que no les corresponde, quedan expeditas las vías de impugnación procedentes.

A la vista de todas estas consideraciones el Tribunal Constitucional emite el siguiente FALLO: 
1. Declarar inconstitucionales:

a) El inciso «y en el artículo segundo» del art. 4.2.

b) El artículo 5 en su totalidad, de acuerdo con lo dicho en el Fundamento Jurídico quinto y, por conexión, todas las remisiones al mismo contenidas en la presente Ley.

c) El inciso final / «sin otro límite que el respeto a la organización determinada por esta Ley»), que aparece tanto en el artículo 20.1.c), como en el art. 32.2, en ambos casos en los términos y con el alcance que se precisan en el Fundamento Jurídico sexto.

d) El inciso final («en todo aquello que su Reglamento Orgánico no disponga lo contrario») del art. 20.2.

e) El inciso final («que regirán en cada provincia en todo aquello en lo que ésta no disponga lo contrario en ejercicio de su potestad de autoorganización») del art. 32.2 .

f) El inciso final del art. 48 («y a través del Ministerio de Administración Territorial»).

2. Declarar que el art. 2.2, no es inconstitucional interpretado en el sentido expuesto en el Fundamento Jurídico tercero, extendiéndose este pronunciamiento, por conexión al art. 25.3.

3. Declarar que no tiene carácter básico el art. 45.2 b) apartados primero y segundo, y que, por tanto, su contenido no es vinculante para las Comunidades Autónomas recurrentes.

4. - Desestimar los recursos en todo lo demás.

VOTO PARTICULAR: Formulado por D. Eugenio Díaz Eimil, para quien:

«Los arts. 20.1.c) y 20.2 de la Ley impugnada guarda fiel conformidad con ese modelo constitucional, no siendo a mi juicio, aceptable afirmar que tales preceptos legales básicos desplazan indebidamente la competencia autonómica sobre la organización municipal a un plano distinto del que constitucionalmente le corresponde, eliminando la posibilidad de todo espacio normativo para la legislación de desarrollo autonómico en esta materia, puesto que la naturaleza supletoria y residual de esa competencia autonómica viene necesariamente determinada por la garantía de la autonomía municipal, la cual exige de manera insoslayable que las Comunidades Autónomas no puedan cubrir más espacio organizativo municipal complementario que aquel que el Municipio no haya complementado... Ello me conduce a entender que dichos preceptos legales son, en su totalidad, constitucionales, cualidad que no extiendo al art. 32.2, puesto que considero que sería muy discutible reconocer a la Provincia el mismo nivel de autonomía que al Municipio garantizado en el art. 140 de la Constitución». 